\title{
EVALUASI IMPLEMENTASI PROGRAM SISTEM PENCATATAN DAN PELAPORAN TERPADU PUSKESMAS
}

\author{
Evi Hasnita \\ STIKes Fort De Kock Bukittinggi \\ evi.hasnita@yahoo.co.id
}

Submitted: 02-08-2018, Reviewer: 06-08-2018, Accepted: 06-08-2019

\begin{abstract}
Program implementation in Koto Type the health center includes several phases of activity, starting from the data collection phase, perekapan, inputting and sending to the Department of Health Kota.dari terms of delivery of the reports is still timely and charging an incomplete report. The purpose of this study to evaluate the implementation of the program recording and reporting system of integrated health centers in health centers katik koto long field,research design is qualitative research with phenomenological. With the number of informen of 7 people, results showed on the input source human resources are lacking, the process of the implementation of the SP2TP not running optimally because still many shortcomings in the planning, recording and reporting so that the effect on the incompleteness and delays in the delivery of the Monthly Report.The conclusion of the research is the implementation of the PHC Koto SP2TP Katik not been implemented optimally. The need for increased availability, power that the implementation processes SP2TP no constraints as well as reports submitted complete and timely.
\end{abstract}

\section{Keywords: $\quad$ Evaluation, SP2TP, completeness, timeliness}

ABSTRAK
Pelaksanaan program SP2TP di Puskesmas Koto Katik meliputi beberapa tahap kegiatan, yaitu dimulai dari tahap pengumpulan data, perekapan,penginputan dan pengiriman ke Dinas Kesehatan Kota.dari segi pengiriman laporan masih belum tepat waktu dan pengisian laporan yang belum lengkap.Tujuan penelitian ini melakukan evaluasi implementasi program sistem pencatatan dan pelaporan terpadu puskesmas di puskesmas koto katik padang panjang.Desain penelitian ini adalah penelitian kualitatif dengan pendekatan fenomenologi. Dengan jumlah informen sebanyak 7.Hasil penelitian menunjukan pada input Sumber daya manusia masih kurang, proses pada pelaksanaan SP2TP belum berjalan maksimal karena masih banyak kekurangan pada perencanaan,pencatatan dan pelaporan sehingga berpengaruh pada ketidaklengkapan dan keterlambatan dalam penyampaian laporan bulanan. Kesimpulan dari hasil penelitian yaitu pelaksanaan SP2TP pada Puskesmas Koto Katik belum terlaksana dengan optimal. Diperlukannya peningkatan ketersediaan, tenaga agar pada proses pelaksanaan SP2TP tidak ada kendala serta laporan yang dikirimkan lengkap dan tepat waktu.

Kata Kunci : Evaluasi, SP2TP, kelengkapan, ketepatan waktu 


\section{PENDAHULUAN}

Menurut Peraturan Menteri

Kesehatan Nomor 75 Tahun 2014 tentang Pusat Kesehatan Masyarakat. Pusat Kesehatan Masyarakat yang selanjutnya disebut Puskesmas adalah fasilitas pelayanan kesehatan yang menyelanggarakan upaya kesehatan masyarakat dan upaya kesehatan perseorangan tingkat pertama, dengan lebih mengutamakan upaya promotif dan preventiv, untuk mencapai derajat kesehatan masyarakat yang setinggitingginya di wilayah kerjanya

Efisiensi waktu dan kecepatan menghasilkan informasi atau laporan kepada pengguna juga bisa terlambat. Salah satu cara untuk mengatasinya adalah dengan cara pengembangan sistem, yaitu menyusun sistem baru untuk menggantikan sistem yang lama secara keseluruhan atau memperbaiki sistem yang telah ada.

Di seluruh dunia, penerapan teknologi informasi dan komunikasi untuk mendukung layanan kesehatan nasional berkembang pesat dan semakin penting. Hal ini terutama terjadi pada saat semua sistem kesehatan menghadapi tantangan ekonomi yang ketat dan tuntutan yang lebih besar untuk memberikan perawatan yang lebih dan lebih baik, terutama kepada mereka yang paling membutuhkan.

Dalam Peraturan Pemerintah RI Nomor 46 Tahun 2014 pasal 1 menyatakan Sistem Informasi Kesehatan adalah seperangkat tatanan yang meliputi data, informasi, indikator, prosedur, perangkat, teknologi, dan sumber daya manusia yang saling berkaitan dan dikelola secara terpadu untuk mengarahkan tindakan atau keputusan yang berguna dalam mendukung pembangunan kesehatan.

Beradasarkan laporan Pusdatin pada tahun 2015 komponen penilaian pelaporan, keterisian variabel pada tingkat provinsi Sumatera Barat belum secara lengkap melaporkan data bulanan, triwulan dan data Umum dengan persentase $89,39 \%$ dari $100 \%$ dengan rincian Data bulanan 90\%, Data Triwulan $84 \%$ dan tahunan 73,68 \%.

Berdasarkan data dan informasi yang didapat dari Dinas Kesehatan Kota Padang Panjang dari 4 Puskesmas yang melaporkan data bulanan SP2TP semua Puskesmas belum secara lengkap mengirimkan data bulanan tersebut. Puskesmas Bukit urungan (79,68\%), Puskesmas Gunung (57,76\%), Puskesmas Kebun Sikolos (36,56\%), Puskesmas Koto Katik ( 29,16\%). Dari data diatas Puskesmas Koto Katik merupakan salah satu diantara Puskesmas yang digolongkan sebagai puskesmas terbawah yang menjalankan program SP2TP dari aspek kelengkapan pelaporan laporan bulanan baik LB1,LB-2, LB-3 dan LB-4. Berdasarkan alasan tersebut maka penulis tertarik untuk melakukan penelitian dengan judul "Evaluasi Implementasi Program Sistem Pencatatan dan Pelaporan Terpadu Puskesmas di Puskesmas Koto Katik Kota Padang Panjang.

\section{METODE PENELITIAN}

Metode yang digunakan pada penelitian ini adalah penelitian Kualitatif dengan pendekatan fenomenolgi dengan melakukan wawancara mendalam, Subyek penelitian ini adalah adalah keseluruhan objek penelitian atau yang akan diteliti, Informan dalam penelitian 
ini yaitu 7 orang yang terdiri, Kepala Puskesmas, koordinator SP2TP dinas kesehatan, Kasubag TU Puskesmas, 1 orang bagian sistem dan informasi puskesmas, 2 orang penanggung jawab program kegiatan puseksmas, dan 1 orang pelaksana kegiatan di luar puskesmas ( petugas program di pustu dan puskeskel) yang berada di wilayah kerja Puskesmas. Penelitian ini menggunakan teknik pengumpulan data primer dan data sekunder berupa wawancara, observasi dan dokumentasi terhadap responden penelitian sedangkan analisis data yang menggunakan pengumpulan data reduksi data, penyajian data, menarik kesimpulan.

\section{HASIL DAN PEMBAHASAN}

A. Masukan (Input)

\section{Sumber Daya Manusia}

Tenaga Keseahtan adalah setiap orang yang mengabdikan diri dalam bidang kesehatan serta memiliki pengetahuan dan atau keterampilan melalui pendidikan di bidang kesehatan yang untuk jenis tertentu memerlukan kewenangan untuk melakukan upaya kesehatan.Berdasarkan hasil penelitian diketahui bahwa jumlah tenaga dalam program SP2TP di Puskesmas Koto Katik hanya ada 1 (satu) orang yang dipegang oleh Kepala Tata Usaha sehingga perlu untuk di tambah mengingat tenaga yang ada mempunyai tugas rangkap pengelolaan SP2TP di Puskesmas Koto Katik.

\section{Sarana}

Sarana dan prasarana merupakan alat pendukung dan pelaksana suatu kegiatan yang disebut juga dengan perlengkapan yang dimiklki oleh organisasi dalam membantu kinerja SDM di dalamnya. sarana di puskesmas Koto Katik bahwa sudah tidak ada kendala dari segi form pencatatan dan alat tulis untuk keperluan pencatatan laporan bulanan. Dari segi komputer juga cukup. Tetapi Puskesmas tidak memiliki buku panduan SP2TP.

\section{Dana}

Pendanaan SP2TP telah sesuai dilakukan yaitu berasal dari APBD yang disalurkan melalui Dinas Kesehatan. hasil penelitian di ketahui bahwa pendanaan dalam pengelolaan SP2TP di Puskesmas Koto Katik cukup. Dana tersebut bersumber dari dana APBD dan dikeola oleh bendahara pembantu pengeluaran.

\section{Kebijakan}

Kebijakan adalah dasar bagi pelaksanaan kegiatan atau pengambilan keputusan dengan maksud untuk membangun suatu landasan yang jelas dalam pengambilan keputusan dan langkah yang diambil . Kebijakan didasarkan pada masalah yang ada di daerah, selanjutnya kebijakan harus secara terus menerus dipantau, direvisi dan ditambah agar tetap memenuhi kebutuhan yang terus berubah. Berdasarkan hasil penelitian Kebijakan khusus tentang SP2TP tidak ada, hanya saja dalam Permenkes No 75 Tahun 2014 
tentang Pusat Kesehatan Masyarakat $\mathrm{Bab} \quad$ VIII menjelasakan tentang Sistem Informasi Puskesmas. Pada ayat 3 dijelaskan bahwa pencatatan dan pelaporan kegiatan Puskesmas.

\section{B. Proses (Process)}

\section{Perencanaan}

Perencanaan

merupakan

mendeskrispikan situasi masa depan, berdasarkan pemahaman atas kondisi saat ini. Mengembangkan kemungkinan dan pemilihan upaya untuk mencapai masa depan, menentukan langkah- langkah kerja untuk mencapai masa depan, memperkirakan kebutuhan sumber daya dan waktu yang diperlukan (Darmawan,2016.p74), Di puskesmas koto katik secara operasional telah ada petugas koordinator SP2TP yang ditunjuk namun untuk koordinator hanya 1 orang sekaligus tugas yang dijalankan oleh koordinator merangkap sebagai penginput data laporan bulanan yang di dapat dari masing-masing program Puskesmas dan bertugas juga dalam pengiriman laporan bulanan ke tingkat Dinas Kesehatan. Diharapkan kepada Puskesmas untuk membagi tugas secara terstruktur sehingga ada pembagian tugas dalam pencatatan laporan sehingga tidak terfokus pada 1 orang.

\section{Pelaksanaan}

Pergerakan dan pelaksanaan merupakan sebuah upaya yang dilakukan sesuai dengan rencana kegiatan yang telah ditetapkan sebelumnya (Darmawan,2016). Hasil wawancara motivasi yang diberikan
Puskesmas hanya berupa dorongan semata, sedangkan dana yang dimaksud oleh kepala Puskesmas pada wawancara mendalam adalah dana program bukan dana khusus untuk pelaksana program

\section{Pencatatan}

Menurut febriyanto (2014) Pencatatan adalah proses dalam mencatat kegiatan pokok puskesmas baik yang dilakukan di dalam gedung maupun di luar gedung puskesmas, puskesmas tempat tidur, dan puskesmas pembantu serta bidan di desa harus dicatat. Dengan demikian perlu adanya mekanisme pencatatan yang baik, formulir yang cukup serta cara isian yang benar dan diteliti. Tahap pencatatan SP2TP di Puskesmas Koto Katik belum sepenuhnya lengkap ada beberapa data yang kosong untuk direkap. Kendala yang seperti ini yang membuat ketidaklengkapan pada pelaporan. Sebaiknya dari Puskesmas memberikan tenggang waktu pada penanggung jawab laporan bulanan dalam penyelesaian pencatatan.

\section{Pelaporan}

Pelaporan atau pembuatan laporan adalah kegiatan untuk menyusun sekumpulan data hasil pencatatan untuk disampaikan kepada pihak terkait sebagai bentuk pertanggungjawaban dan atau pemberitahuan atas kegiatan dan hasil kegiatan yang telah dilaksanakan. Berdasarkan hasil wawancara Pelaporan setiap pelaksana kegiatan Puskesmas baik 
di dalam maupun luar puskesmas melaporkan hasil laporannya tiap bulan. Pelaporan yang disampaikan tiap bulannya disampaikan dalam bentuk format yang telah disediakan oleh dinas kesehatann. Laporan yang dibuat pada format yang telah disediakan oleh Dinas kesehatan Kota dan yang sudah di bakukan. Pencatatan yang masih manual menyebabkan keterlambatan pada pelaporan tingkat dinas Kesehatan kota. Tetapi pelaporan yang disampaikan oleh bidan Poskeskel belum berupa format Seharusnya Puskesmas membagikan fomat secara terpadu pada bidan yang ada di Poskeskel supaya pencatatan langsung dimasukan dalam format sehingga pemegang program di Puskesmas tidak mencatat dua kali dan itu juga bisa menghemat waktu penyelesaian.

\section{Pengawasan}

Fungsi pengawasan adalah meminimumkan kegagalan. Ketika organisasi melakukan kegiatan atau suatu program misalnya, organisasi pastilah berharap agar kegagalan dapat ditekan seminimal mungkin (Darmawan,2016). Berdasarkan hasil penelitian pada pencatatan dan pelaporan SP2TP perlu ada pengawasan yang bertujuan untuk meminimalkan kesalahan pada pencatatan dan pelaporan. pengawasan yang dilakukan berupa pengawasan tertulis terhadap laporan yang akan dikirim ke Dinas Kesehatan Kepala Puskesmas memeriksa kembali sebelum ditanda tangani. Seharusnya pengawasan yang dilkukan bukan hanya tertulis saja tetapi juga perlu secaa lisan dengan cara menanyakan langsung kepada yang berkepentingan.

\section{Keluaran (Output) \\ 1. Monitoring evaluasi}

Monev adalah sebuah usaha yang memastikan jalannya sebuah aktifitas sesuai target yang ingin dicapai. Tujuannya yaitu memberi pemahaman tentang langkah-langkah persiapan,pelaksanaan dan pelaporan hasil program (mengetahui kelemahan dan kekuatan dari program yang ingin dicapai). Dari hasil penelitian monev. Monev yang dilakukan hanya fokus pada kegiatan program Puskesmas saja yang dilakukan setiap bulan melalaui Lokmin bulanan. Sedangkan untuk evaluasi SP2TP sendiri belum pernah dilakukan. di puskesmas Koto Katik monev yang dilakukan hanya fokus pada program saja bukan ke SP2TP seharusnya dilakukan monev juga harus di fokuskan program SP2TP bukan hanya kegiatan Puskesmas saja, karena dengan melakukan evaluasi secara berkala dapat mempengaruhi hasil dari pelaporan laporan bulanan.

\section{Kelengkapan dan ketepatan waktu}

Menurut penelitian Febryanto (2014) hal yang menyebabkan laporan SP2TP terlambat dikirim karena tenaga pengelola SP2TP sedikit, hal tersebut terjadi karena pekerjaan yang merangkap serta kelengkapan laporan SP2TP secara umum masih belum terpenuhi karena belum semua 
dari format yang dikirimkan dinas kesehatan dikirimkan kembali oleh masing-masing Puskesmas. Dari hasil penelitian kelengkapan dari laporan bulanan bisa dikatakan sudah lengkap. Walaupun dalam waktu 1 tahun masih ada juga laporan yang dikirim kurang lengkap tetapi itu tidak sering terjadi. ketepatan waktu dalam pengiriman laporan SP2TP mulai dari jenjang administrasi yang terbawah sampai ke dinas kesehatan kabupaten sangatlah penting, karena informasi yang telah usang tidak akan mempunyai nilai lagi. Dari segi kelengkapan Data yang disampaikan harus lengkap. Suatu informasi yang dihasilkan oleh sebuah system informasi dapat dikatakan berkualitasjika informasi yang dihasilkan bersifat lengkap.

\section{SIMPULAN}

1. Input dalam pelaksanaan SP2TP di Puskesmas Koto Katik diketahui bahwa kurangnya sumber daya manusia (SDM) dalam pengelolaan SP2TP, petugas juga belum pernah mengikuti pelatihan, tidak adanya buku pedoman yang dimilki oleh pengelola SP2TP serta pendanaan berasal dari APBD yang dikelola oleh bendahara pembantu pengeluaran. Dan tidak adanya kebijakan khusus yang mengatur SP2TP.

2. Proses SP2TP di puskesmas Koto Katik perencanaan dalam menentukan stafnya belum terorganisasi dikarenakan jumlah staff untuk SP2TP itu sendiri hanya 1 orang, puskesmas juga mempunyai batasan tanggal dalam pelaporan laporan bulanan, dalam pelaksanaannya motivasi seorang atasan sangat dibutuhkan agar prosesnya berjalan sesuai yang diinginkan, pada proses pencatatan dan pelaporan kendalanya masih ada keterlambatan dan ketidaklengkapan laporan walaupun itu tidak sering terjadi dalam jangka 1 tahun, serta pengawasan masih tetap dilakukan pada pencatatan dan pelaporan SP2TP dari segi kelengkapan pelaporan.

3. Output yang dihasilkan oleh proses adalah monitoring evaluasi tidak difokuskan pada SP2TP tetapi lebih kepada kegiatan program Puskesmas dari kelengkapan dan ketepatan waktu masih ada terjadi walaupun itu sering.

\section{UCAPAN TERIMA KASIH}

Terima kasih diucapkan kepada LPPM STIKes Fort De Kock Bukittinggi dan informan dari Puskesmas yang terkait sehingga penelitian ini dapat berjalan dengan lancar.

\section{DAFTAR PUSTAKA}

Azwar,A. 2010. Pengantar Administrasi Kesehatan. Tangerang: Binarupa Aksara

Barsasella, Diana. 2012. Sistem Informasi Kesehatan. Jakarta: Mitra Wacana Medika

Darmawan,Ede Surya. dan Sjaaf, Amal Chalik. 2016. Administrasi Kesehatan Masyarakat. Jakarta: PT 
Raja Grafindo Persada. http://www.who.int/countries/idn/e $\mathrm{n} /$ Kemenkes RI. Tantangan e-kesehatan di Indonesia. Jakarta: 2016

Kemenkes RI. Pusat Data dan Informasi.Jakarta: 2016

Khalifa,MD,2013.Bariers to health Information System and Electronic Medical Records Implementation. (21), 333-342

Mangaro,H.A.,

Setyowati,M.2014.Evaluasi

$\begin{array}{lcr}\text { Penerapan } & \text { Simpus } & \text { Untuk } \\ \text { Pencatatan } & \text { dan } & \text { Pelaporan } \\ \text { Puskesmas di } & \text { Puskesmas } \\ \text { Pandanaran Semarang } & \text { Tahun } \\ \text { 2014. Artikel } & \text { Ilmiah.FKM } \\ \text { Universitas } & \text { Dian } \\ \text { Nuswantoro.Semarang } & \end{array}$

Muninjaya, Gde.2004. Manajemen Kesehatan. Jakarta: EGC

Notoatmodjo, Soekidjo. 2012. Metodologi Penelitian Kesehatan. Jakarta: Rineka Cipta

Permenkes RI. Peraturan Menteri kesehatan tahun 2015, tentang Peta Jalan Sistem Informasi Kesehatan Tahun 20152019.Jakarta: 2015

Permenkes RI. Peraturan Menteri kesehatan tahun 2016, tentang Pedoman Manajemen Puskesmas.Jakarta: 2016

Puspita.S.J,et al. 2013. Kajian Sistem Pencatatan Dan pelaporan Terpadu
Puskesmas Penumping Kota

Surakarta. Artikel Ilmiah Apikes Citra Medika Surakarta

Sandra, V.B.2013.The electronic health record and its contribution to healthcare Information System Interoperability,(9), 940-948

Sari,I.R.2016.Sistem Informasi Pencatatan Dan Pelaporan Puskesmas Program Kesehatan Ibu Dan Anak,(7),251-256

Saryono dan Anggraeni, Mekar dwi.2013. Metode Penelitian Kualitatif dan Kuantitatif dalam Bidang Kesehatan. Yogyakarta: Nuha Medika

Setiawan,Ari. dan Saryono.2011. Metodologi Penelitian Kebidanan. Yogyakata: Nuha Medika

Sugiyono.2011. Metode Penelitian Pendidikan Pendekatan Kuantitatif-Kualitatif dan R\&D. Bandung: Alfabeta

Sulistyaningsih. 2011. Metodologi Penelitian Kebidanan KuantitatifKualitatif. Yogyakarta: Graha Ilmu Suryani,N.D.,Solikhah.Sistem

Pencatatan Dan Pelaporan Terpadu Puskesmas,(7) 27-32

Yasmin,F.2016.Hubungan Jumlah Tenaga Administarsi Manajemen Dan Sarana Prasarana Dengan Keterlambatan Dan Ketidaklengkapan Sistem Pencatatan Dan Pelaporan Terpadu, (7),41-48. 